\title{
Unil
}

UNIL | Université de Lausanne

Unicentre

CH-1015 Lausanne

http://serval.unil.ch

Year : 2014

\section{ROLE OF VITREORETINAL SURGERY IN MAXIMI ZING TREATMENT OUTCOME FOLLOWING COMPLICATIONS AFTER PROTON THERAPY FOR UVEAL MELANOMA}

\author{
TRAN Bao-Khanh
}

\begin{abstract}
TRAN Bao-Khanh, 2014, ROLE OF VITREORETI NAL SURGERY IN MAXIMI ZING TREATMENT OUTCOME FOLLOWING COMPLICATIONS AFTER PROTON THERAPY FOR UVEAL MELANOMA
\end{abstract}

Originally published at: Thesis, University of Lausanne Posted at the University of Lausanne Open Archive http://serval.unil.ch Document URN : urn:nbn:ch: serval-BIB_5AB4F051956B9

\section{Droits d'auteur}

L'Université de Lausanne attire expressément l'attention des utilisateurs sur le fait que tous les documents publiés dans I'Archive SERVAL sont protégés par le droit d'auteur, conformément à la loi fédérale sur le droit d'auteur et les droits voisins (LDA). A ce titre, il est indispensable d'obtenir le consentement préalable de l'auteur et/ou de l'éditeur avant toute utilisation d'une oeuvre ou d'une partie d'une oeuvre ne relevant pas d'une utilisation à des fins personnelles au sens de la LDA (art. 19, al. 1 lettre a). A défaut, tout contrevenant s'expose aux sanctions prévues par cette loi. Nous déclinons toute responsabilité en la matière.

\section{Copyright}

The University of Lausanne expressly draws the attention of users to the fact that all documents published in the SERVAL Archive are protected by copyright in accordance with federal law on copyright and similar rights (LDA). Accordingly it is indispensable to obtain prior consent from the author and/or publisher before any use of a work or part of a work for purposes other than personal use within the meaning of LDA (art. 19, para. 1 letter a). Failure to do so will expose offenders to the sanctions laid down by this law. We accept no liability in this respect. 
UNIVERSITE DE LAUSANNE - FACULTE DE BIOLOGIE ET DE MEDECINE

Service universitaire d'ophtalmologie

\section{ROLE OF VITREORETINAL SURGERY IN MAXIMIZING TREATMENT OUTCOME FOLLOWING COMPLICATIONS AFTER PROTON THERAPY FOR UVEAL MELANOMA}

\section{THESE}

préparée sous la direction du Professeur Thomas J. Wolfensberger (avec la collaboration du Docteur Ann Schalenbourg, du Docteur Etienne Bovey et du Professeur Léonidas Zografos) et présentée à la Faculté de biologie et de médecine de l'Université de Lausanne pour l'obtention du grade de

DOCTEUR EN MEDECINE

par

Bao-Khanh TRAN

Médecin diplômé de la Confédération Suisse

Originaire de Lausanne (Vaud)

Lausanne

2014

$$
2 \text { - FEV. } 2015
$$

\section{THESES}


UNIVERSITE DE LAUSANNE - FACULTE DE BIOLOGIE ET DE MEDECINE

Service universitaire d'ophtalmologie

\section{ROLE OF VITREORETINAL SURGERY IN MAXIMIZING TREATMENT OUTCOME FOLLOWING COMPLICATIONS AFTER PROTON THERAPY FOR UVEAL MELANOMA}

\section{THESE}

préparée sous la direction du Professeur Thomas J. Wolfensberger

(avec la collaboration du Docteur Ann Schalenbourg, du Docteur Etienne Bovey et du Professeur Léonidas Zografos)

et présentée à la Faculté de biologie et de médecine de l'Université de Lausanne pour l'obtention du grade de

DOCTEUR EN MEDECINE

par

Bao-Khanh TRAN

Médecin diplômé de la Confédération Suisse

Originaire de Lausanne (Vaud)

Lausanne 


\section{Unil}

UNIL | Université de Lausanne

Faculté de biologie et de médecine

Ecole Doctorale

Doctorat en médecine

\section{Imprimatur}

$V u$ le rapport présenté par le jury d'examen, composé de

Directeur de thèse Monsieurle Professeur Thomas Wolfensberger

Co-Directeur de thèse

Expert

Monsieur le Professeur René-Olivier Mirimanoff

Directrice de l'Ecole Madame le Professeur Stephanie Clarke doctorale

la Commission MD de l'Ecole doctorale autorise l'impression de la thèse de

\section{Monsieur Bao-Khanh TRAN}

intitulée

Role of vitreoretinal surgery in maximizing treatment outcome following complications after proton therapy for uveal melanoma

Lausanne, le 25 novembre 2014

pour Le Doyen

de la Faculté de Biologie et de Médecine

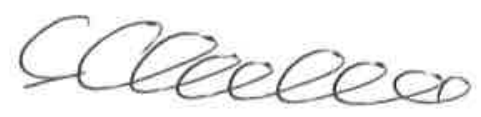

Madame le Professeur Stephanie Clarke Directrice de l'Ecole doctorale 


\section{Rôle de la chirurgie vitro-rétinienne dans la prise en charge des complications induites par la protonthérapie dans le cadre du mélanome de l'uvée}

\section{Résumé}

L'utilisation de faisceaux de protons accélérés dans le traitement des mélanomes de l'uvée a été utilisée pour la première fois en Suisse (et par ailleurs en Europe) en 1984. Depuis, la protonthérapie a constamment évolué avec des logiciels toujours plus performants et précis pour devenir à l'heure actuelle le traitement de référence pour ce type de tumeurs. Ainsi, jusqu'à ce jour, l'Institut Paul Scherrer à Villigen a traité plus de 7000 cas de tumeurs oculaires.

Mais la protonthérapie, aussi efficace soit-elle avec un taux de guérison de plus de $98 \%$, comporte malheureusement un certain nombre d'effets secondaires et indésirables pouvant parfois mener le patient jusqu'à l'énucléation secondaire. De la simple dermatite actinique à l'hémorragie intravitréenne massive, les complications induites sont pour la plupart bien connues et documentées mais leurs prises en charge, notamment sur un organe préalablement irradié diffèrent. Alors que nous avons beaucoup de recul sur la protonthérapie, la gestion de ses complications reste propre à chaque centre de soin et n'est que très peu documentée.

Les complications majeures de la protonthérapie qui ont nécessité une prise en charge par le chirurgien vitrorétinien représentent souvent un défi majeur. Bien que rares, puisqu'elles ne représentent que $2 \%$ de notre collectif, celles-ci peuvent avoir de lourdes conséquences. Par exemple, une hémorragie intravitréenne massive, complication la plus fréquente dans notre série, compromet l'observation de la tumeur au fond d'œil et empêche le bon suivi oncologique.

La chirurgie vitrorétinienne a alors pour mission, de restaurer la transparence des milieux, élément indispensable à l'ophtalmologue pour le suivi clinique, iconographique et radiologique des mélanomes de l'uvée. Secondairement, cette chirurgie permet parfois d'augmenter l'acuité visuelle de l'œil malade.

La chirurgie vitrorétinienne est un précieux atout pour l'oncologue et permet d'éviter une énucléation secondaire. Elle participe ainsi à la prise en charge globale du patient atteint de mélanome de l'uvée. 


\section{ROLE OF VITREORETINAL SURGERY IN MAXIMIZING TREATMENT OUTCOME FOLLOWING COMPLICATIONS AFTER PROTON THERAPY FOR UVEAL MELANOMA}

BAO-KHANH TRAN, MD, ANN SCHALENBOURG, MD, ETIENNE BOVEY, MD, LEONIDAS ZOGRAFOS, MD, THOMAS J. WOLFENSBERGER, MD

Purpose: To assess the role of vitreoretinal surgery in maximizing treatment outcome following complications after proton therapy for uveal melanoma and to evaluate its safety.

Methods: Retrospective chart study on 21 patients ( $2 \%$ of a total of 1,005 treated by proton therapy between January 2003 and August 2007) who had developed a complication requiring vitreoretinal surgery. Mean/median total follow-up after irradiation was 43/43 months (range, 12-70 months).

Results: Indications for surgery included vitreous hemorrhage $(n=13)$, epimacular membrane $(n=5)$, rhegmatogenous retinal detachment $(n=1)$, combined vitreous hemorrhage with total serous retinal detachment $(n=1)$, and vitritis $(n=1)$. Mean/median interval for vitreoretinal surgery after irradiation was 21/20 months (range, 4-45 months), and mean/ median follow-up after pars plana vitrectomy was 22/23 months (range, 2-56 months). Pars plana vitrectomy was combined with retinal photocoagulation $(n=5)$, air/gas $(n=5)$, or silicone oil tamponade $(n=1)$. Mean Snellen visual acuity was $20 / 200(0-20 / 40)$ before and 20/100 (0-20/25) after pars plana vitrectomy. A transient postoperative rise in intraocular pressure was measured in seven patients. Four patients developed phthisis bulbi.

Conclusion: Vitreoretinal surgery was efficient in maximizing treatment outcome after proton therapy, as it allowed a better oncologic follow-up. Pars plana vitrectomy permitted panretinal photocoagulation to avoid neovascular glaucoma or retinal detachment repair. Macular surgery improved visual acuity, especially in anterior melanoma, whereas repeated surgery may increase the risk of enucleation.

RETINA 33:1777-1783, 2013

$\mathrm{U}$ veal melanoma (UM) is the most frequent intraocular malignancy in ophthalmologic practice, mainly encountered in adult white populations with an annual incidence of six new cases per million. ${ }^{1}$ Standard treatment is radiotherapy, using plaques or proton beam, or enucleation with similar survival rates

From the Jules-Gonin Eye Hospital, University of Lausanne, Lausanne, Switzerland.

Presented at the Club Jules-Gonin, XXVIIth Meeting, Kyoto, Japan, November 6, 2010.

B.-K. Tran and A. Schalenbourg contributed equally to this study.

None of the authors have any financial/conflicting interests to disclose.

Reprint requests: Thomas J. Wolfensberger, MD, Jules-Gonin Eye Hospital, University of Lausanne, Avenue de France 15, Lausanne CH-1004, Switzerland; e-mail: thomas.wolfensberger@fa2.ch for both methods. ${ }^{2}$ External proton beam radiotherapy delivers a uniform irradiation to the target volume, with a good sparing of uninvolved eye tissues. As $\mathrm{UM}$ is a radioresistant tumor requiring high radiation doses, proton therapy allows for tumors with a large volume or a shape or location unfit for brachytherapy, also being treated conservatively. ${ }^{3}$

The results of proton therapy figure among the best of any conservative oncologic treatment techniques, with local tumor recurrence only ranging from $1 \%$ to $5 \%{ }^{3}$ Eye retention rate varies from $85 \%$ to $100 \%$ and is mainly related to tumor size, proximity to the disk, and the extent of retinal detachment (RD) at treatment time. The main cause of secondary enucleation is neovascular glaucoma. ${ }^{3-5}$ Functional prognosis is often 
poor, with a final Snellen visual acuity of $20 / 100$ in $<50 \%$ of the patients. ${ }^{6}$

Sight-threatening tumor and radiation-induced complications include $\mathrm{RD}$, maculopathy, papillopathy, cataract, glaucoma, vitreous hemorrhage $(\mathrm{VH})$, and the recently described "toxic tumor syndrome."7 Their occurrence depends primarily on tumor location and size. There are to date no precise data available on the surgical management of vitreoretinal (VR) complications after proton therapy. The aim of this study was therefore to assess the role of VR surgery in maximizing treatment outcome following complications after proton beam irradiation for UM.

\section{Patients and Methods}

We scanned retrospectively through the data of 1,005 consecutive patients who were treated for UM between January 2003 and August 2007. We identified and investigated 21 patients/21 eyes $(2 \%)$ that had required VR surgery for a tumor or radiation-related complication. All patients were seen at the Ocular Oncology Unit of the Jules-Gonin Eye Hospital (Lausanne, Switzerland), and investigations and treatment included the following: confirmation of UM diagnosis, tantalum clip surgery, ophthalmic oncologic follow-up, and VR surgery. Proton beam radiotherapy was performed at the Paul Scherrer Institute (Villigen, Switzerland), according to a standard protocol prescribing 60 cobalt gray equivalent in 4 fractions on 4 consecutive days. ${ }^{8}$ Pars plana vitrectomy (PPV) was performed according to the same standardized protocol as for eyes without an intraocular tumor by two surgeons (E.B. and T.J.W.). In the cases presenting an anterior ciliochoroidal tumor, the insertion of the PPV instruments was planned in a manner as to avoid the tumor site.

The mean age of our 21 patients (male to female ratio: 12:9) at the time of melanoma diagnosis was 53 years (range, $19-69$ years). The main outcome measures were indications for surgery, time interval after proton therapy, and specific VR surgical modalities. We also analyzed clinical follow-up data, including Snellen best-corrected visual acuity, intraocular pressure (IOP), and final eye retention. The mean/median total follow-up time after irradiation was $43 / 43$ months (range, 12-70 moths).

\section{Results}

Indications for VR surgery (Table 1) included VH $(\mathrm{n}=13)$, rhegmatogenous $\mathrm{RD}(\mathrm{n}=1)$, combined $\mathrm{VH}$ with total serous RD $(n=1)$, vitritis of undetermined

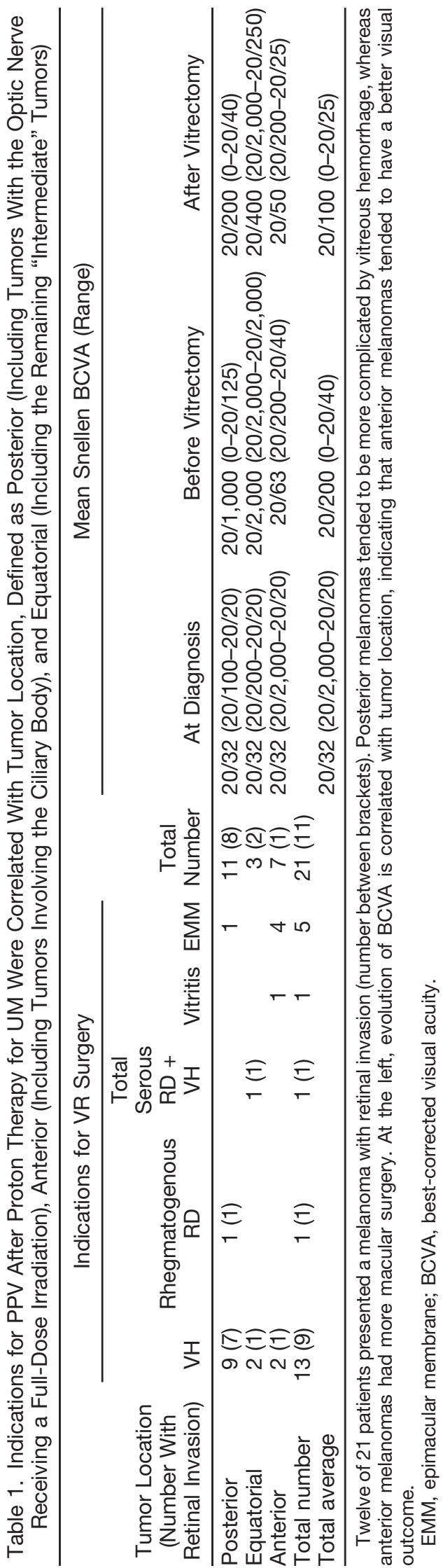


origin $(n=1)$, and epimacular membrane $(n=5), 2$ of which were associated with a lamellar macular hole. Indications for PPV were correlated with tumor location, revealing that posterior melanomas tended to lead more often to $\mathrm{VH}$, whereas anterior melanomas were associated more often with macular surgery. From the 14 patients presenting a $\mathrm{VH}, 9$ were presumed to come from tumor vessels or retinal vessels overlying a tumor with retinal invasion (of which the posterior melanomas were originally called "Knapp-Ronne" type melanoma ${ }^{9}$ ) (Figure 1), 3 were only associated with ischemic retinopathy, and 2 cases presented both complications. The former were treated with vitrectomy only, in one case with coagulation of visible tumor vessels, the others presumably having scarred after radiotherapy. The latter five cases, presenting proliferative radiation retinopathy, were at the end of their PPV treated with panretinal photocoagulation and one of them also with bevacizumab. This was the only case that ultimately developed neovascular glaucoma. Three of the five patients presenting $\mathrm{VH}$ and ischemia had at the same time rubeosis iridis without glaucoma, and in one of those three, the angle was involved.

The mean/median interval for the appearance of these complications following proton therapy and the subsequent VR surgery was 21/20 months (range, 4-45 months), with a mean/median follow-up time after PPV of 22/23 months (range, 2-56 months). Diagnosis was usually made after visual symptoms had been noticed by the patient, although some complications were only discovered during a routine oncologic follow-up examination.

Seven patients $(33 \%)$ presented an anterior ciliochoroidal tumor. Table 2 summarizes the variations on standard PPV that were applied and the corresponding number of patients. One patient with an anterior melanoma and chronic inflammation had a second vitrectomy to remove membranes provoking pupillary seclusion around his lens implant. The three other patients, having had repeated PPV because of recurrent $\mathrm{VH}$ (average $\mathrm{VH}$ duration 4.5 months, range, 3-6 months), ultimately all developed phthisis
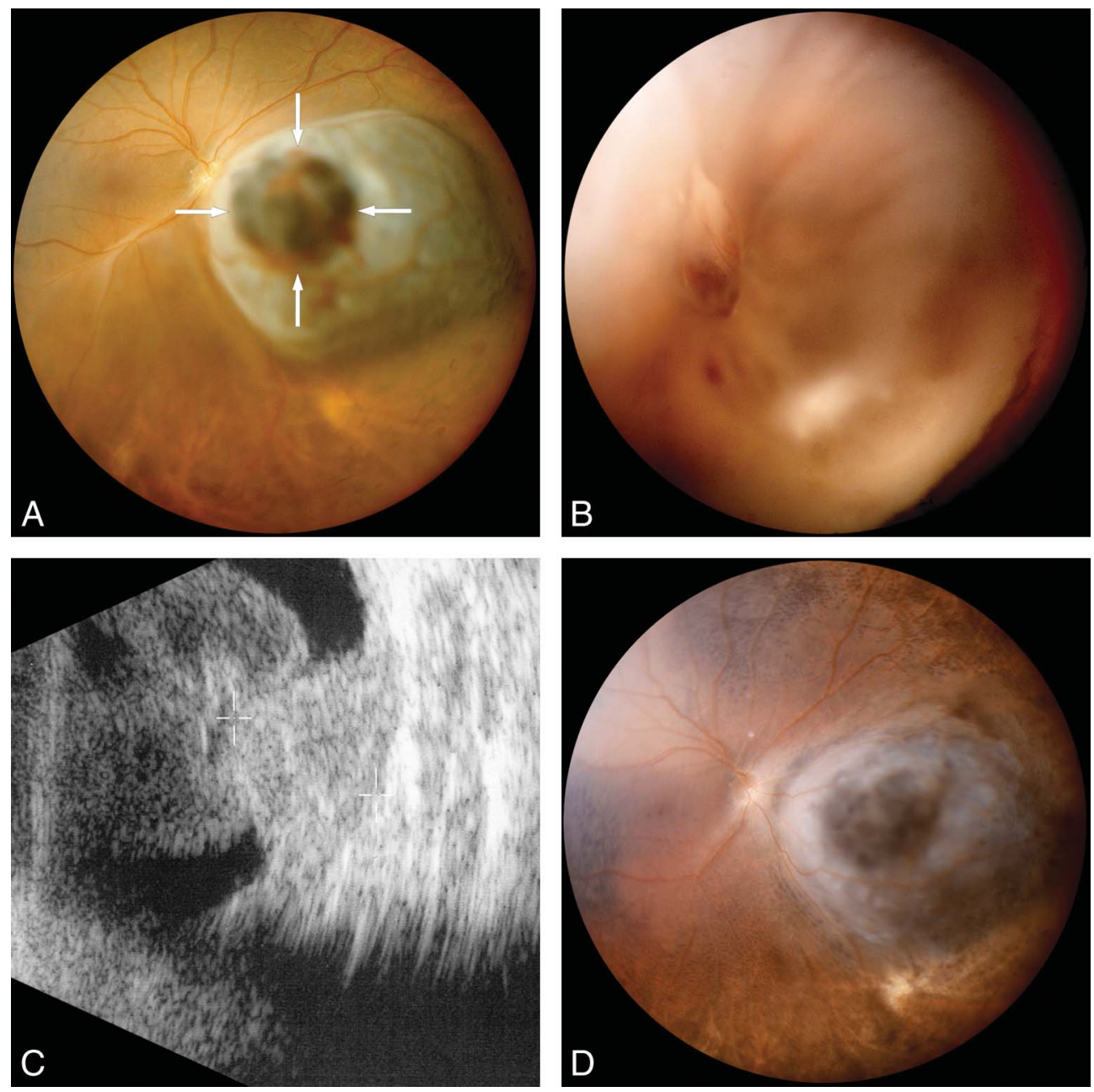

Fig. 1. Panoramic fundus pictures (Panoret camera) of a $\mathrm{VH}$ after proton therapy of a Knapp-Ronne type melanoma. A. A 55-year-old man had a parapapillary, nasal choroidal melanoma, presenting a hemorrhage at its surface and an invasion of the retina (white arrows). Despite the presence of a secondary serous RD, his best-corrected visual acuity (BCVA) was 20/25. He was treated with proton therapy. B. Six months later, his BCVA had dropped to light perception, related to a VH. C. On B-scan ultrasonography, the $\mathrm{VH}$ was shown to originate from the apex of the tumor, which had regressed from an original thickness of $8.4 \mathrm{~mm}$ to $7.8 \mathrm{~mm}$. A simple uneventful vitrectomy was performed. D. Five months later, the tumor scar remained perfectly visible, with a BCVA at 20/400, related to retinal atrophy. 
Table 2. Summarizes the Technical Variations on Standard PPV Applied During the First Vitrectomy and the Corresponding Number of Patients, Including the Number of Phacoemulsifications and Intravitreal Injections of Anti-VEFGs and Triamcinolone

\begin{tabular}{|c|c|c|c|c|c|c|c|}
\hline First Vitrectomy Procedure & Number & +Phaco & +Bevacizumab & +Triamcinolone & $\begin{array}{l}\text { 2nd } \\
\text { PPV }\end{array}$ & $\begin{array}{l}\text { 3rd } \\
\text { PPV }\end{array}$ & $\begin{array}{c}\text { Phthisis } \\
\text { Bulbi }\end{array}$ \\
\hline Simple vitrectomy & 10 & 1 & & 1 & 2 & & 1 \\
\hline Vitrectomy with silicone tamponade & 1 & & & & & & \\
\hline Vitrectomy with air/gaz tamponnade & 5 & & & & & & \\
\hline Vitrectomy with laserphotocoagulation & 4 & 1 & 1 & & 1 & & 2 \\
\hline $\begin{array}{l}\text { Vitrectomy with air tamponnade and } \\
\text { laserphotocoagulation }\end{array}$ & 1 & 1 & & 1 & 1 & 1 & 1 \\
\hline Total number & 21 & 3 & 1 & 2 & 4 & 1 & 4 \\
\hline
\end{tabular}

There were 4 patients requiring a second and one a third vitrectomy, 3 of whom developed phthisis bulbi.

bulbi. No internal tumor resection was performed in this series.

Pars plana vitrectomy and phacoemulsification were combined in 3 cases (14\%) during the first and in 2 cases $(10 \%)$ during the second vitrectomy, when lens opacities were too significant to allow correct fundus visualization.

Table 1 summarizes the evolution of mean Snellen best-corrected visual acuity from the time of UM diagnosis to before and after PPV, correlating best-corrected visual acuity with tumor location. Average visual acuity evolved from 20/32 (20/2,000-20/20) at the time of UM diagnosis till 20/200 (0-20/40) before and 20/100 (0-20/25) after vitrectomy. Main causes for loss of visual acuity at the time of UM diagnosis were exudative RD and lens opacities. In this study, visual acuity of 11 patients improved (52\%), 5 patients remained stable $(24 \%)$, and 5 patients deteriorated (24\%) after PPV (Figure 2). Radiation retinopathy, macular atrophy, and lens opacities were the main causes preventing visual acuity from improving more than to a mean of 20/100 after PPV.

Figure 3 shows the IOP evolution at the time of UM diagnosis, before, immediately after, and 4 months after vitrectomy, with mean IOP (in red) evolving from $13 \mathrm{mmHg}( \pm 3 \mathrm{SD})$ at the time of diagnosis to $15 \mathrm{mmHg}( \pm 3 \mathrm{SD})$ preoperatively, $20 \mathrm{mmHg}( \pm 8 \mathrm{SD})$ postoperatively, and $15 \mathrm{mmHg}( \pm 3 \mathrm{SD}) 4$ months later. Seven patients presented a transient postoperative rise in IOP above $21 \mathrm{mmHg}$ of which 6 could be normalized with medical treatment. One patient with an inferotemporal anterior ciliochoroidal melanoma received a Baerveldt tube into the anterior chamber 14 months after PPV for an epiretinal membrane related to a "toxic tumor syndrome" with fibrosis and pupillary block.

Postoperative follow-up data showed that 4 of our 21 patients developed phthisis bulbi (19\%), 3 of whom underwent secondary enucleation 33,43 , and 47 months after proton therapy (14\%), respectively,
Fig. 2. Graphic illustrating the evolution of Snellen bestcorrected visual acuity (BCVA) at the time of UM diagnosis as well as before and after PPV for each of the 21 operated patients with mean visual acuity (red line) evolving from $20 / 32$, to 20/200 before, and 20/100 after PPV, respectively. The only patient with an inversed BCVA curve evolving from hand movements at diagnosis to $20 / 40$ before and 20/100 after PPV had an anterior UM complicated by a dense $\mathrm{VH}$ at presentation, and he underwent PPV when the hemorrhage had already partially resolved. At his postoperative control examination, his secondary lens opacities had so much increased that his BCVA was lower than before PPV.

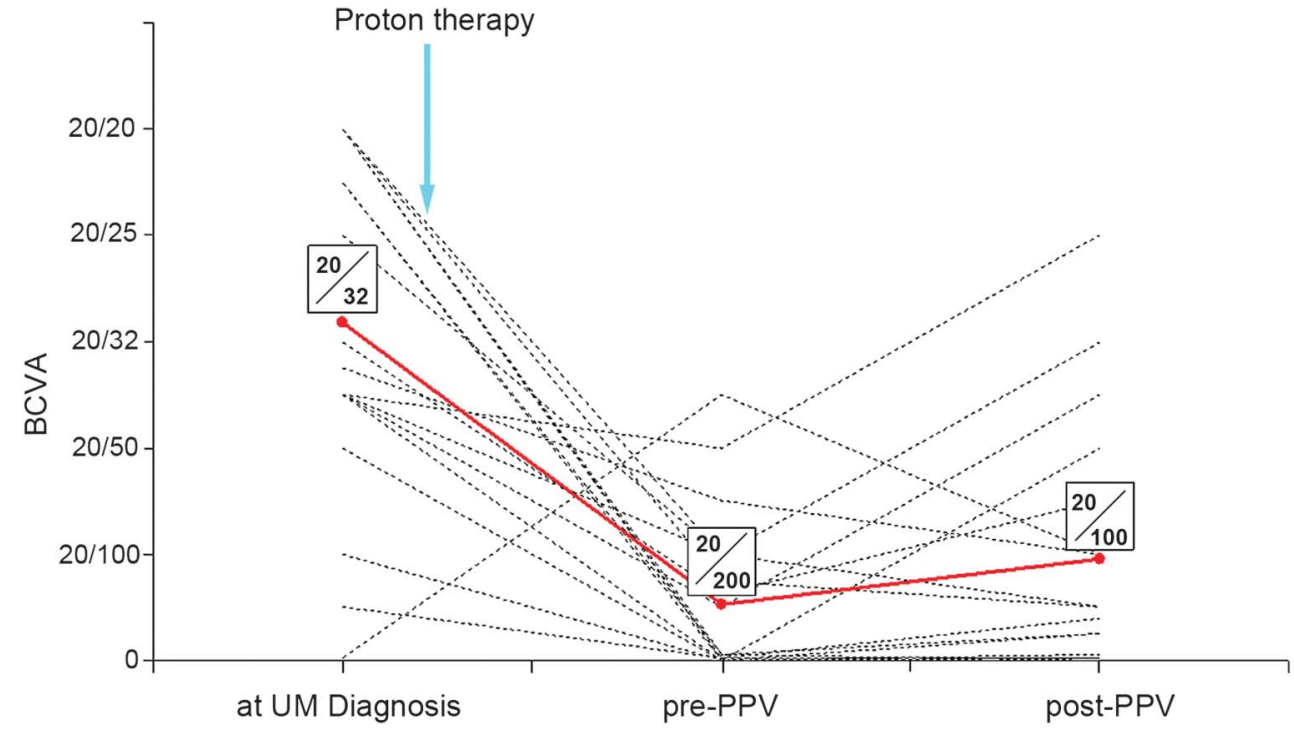




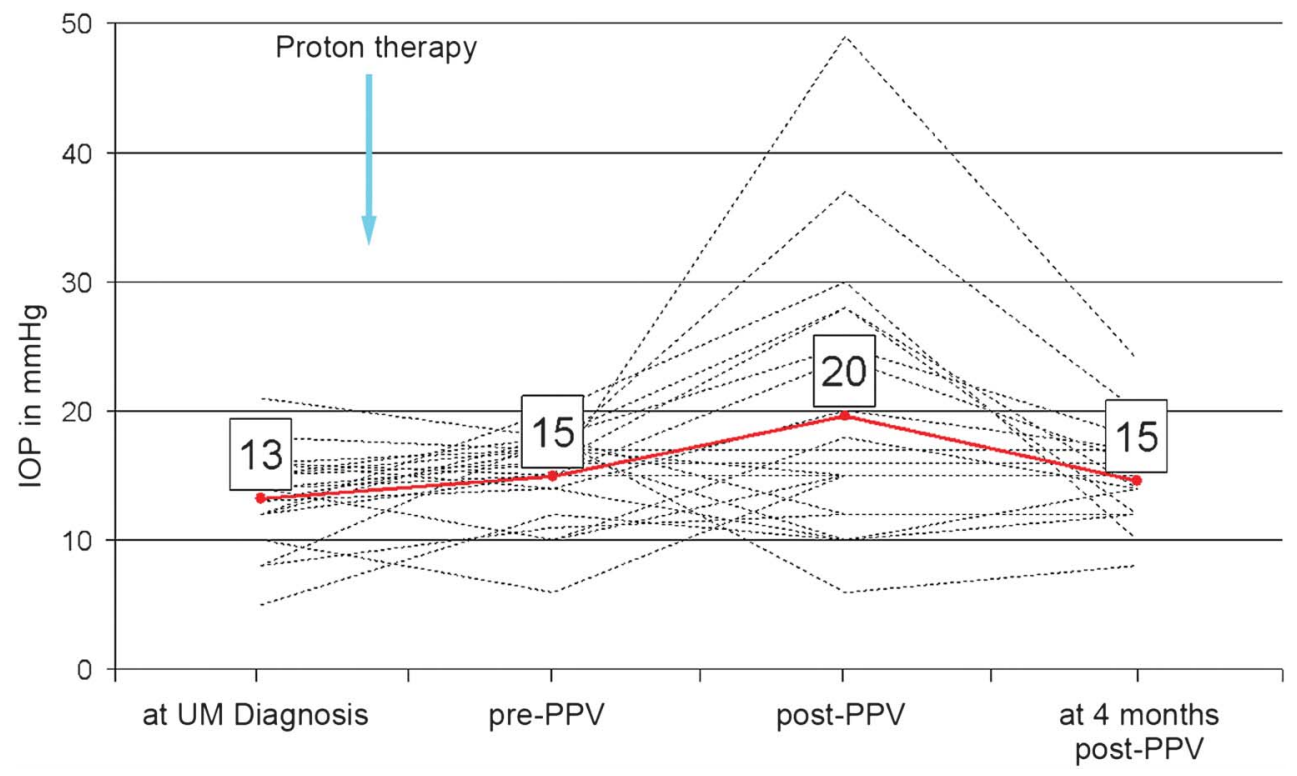

Fig. 3. Graphic showing IOP evolution at the time of UM diagnosis, before, immediately after, and 4 months after PPV, with a mean IOP (red line) of $13,15,20$, and $15 \mathrm{mmHg}$, respectively. and the fourth patient wearing a cosmetic contact lens. Two belonged to the 7 patients with a postoperative rise in IOP. All 4 were women who had undergone vitrectomy, respectively, 6, 3, 5, and 3 months after developing a dense $\mathrm{VH}$. One was related to an anterior tumor recurrence of an equatorial melanoma, treated a second time by proton therapy. The other 3 patients presented a posterior melanoma complicated by uncontrollable proliferative radiation retinopathy, with recurrent VHs, multiple interventions, and one of whom developed neovascular glaucoma. Three of 21 patients presented liver metastases at 11, 24, and 54 months after proton therapy.

\section{Discussion}

This study assesses the role of VR surgery in maximizing treatment outcome following complications after proton beam irradiation for UM. Analyzing the indications, surgical technique, results, and safety of VR surgery in the management of these complications, our study of 1,005 consecutive patients, treated between January 2003 and August 2007, showed that only 21 patients (2\%) underwent VR surgery, illustrating why very few articles related to the subject exist in the literature. It is interesting to note that the majority of publications on this subject are concerned with complications after plaque radiotherapy or other conservative treatments. In contrast, data on the surgical management of complications after proton therapy are scarce.

Haimovici described 10 patients with UM presenting rhegmatogenous $\mathrm{RD}$ simultaneously to $(\mathrm{n}=4)$ or after $(n=6)$ radiation therapy (protons to iodine plaque ratio: 7:3). Only 1 of 10 had PPV and consequently proton therapy, and the authors concluded that because of the rare occurrence of rhegmatogenous $\mathrm{RD}$ in patients with UM, the development of retinal breaks and detachment was unlikely to be related to the tumor or its treatment. ${ }^{10}$ The fact that our series contains only one similar case confirms that impression. In 2 recent publications, which addressed the role of PPV performed on patients with UM after plaque radiotherapy, 1 study showed that 74 patients of 3,707 (2\%) had undergone vitrectomy because of VH, leading to complete resolution in 53 cases $(72 \%) .{ }^{11}$ The other study demonstrated that 29 patients of 3,841 treated UM eyes $(0.8 \%)$ underwent PPV because of proliferative radiation retinopathy. ${ }^{12}$ However, no further details on these "PPV subgroups" are reported. In a case series of 9 treated posterior UM patients (7 with plaque and 2 with transpupillary thermotherapy), Foster et $\mathrm{al}^{13}$ report a similar indication profile as ours: VH $(n=5)$, macular surgery $(n=3)$, and rhegmatogenous $\mathrm{RD}(\mathrm{n}=1)$, with vitrectomy being performed at a mean interval of 24.7 months (range, 7-47 months) after melanoma treatment, which is about 4 months longer than our mean interval.

In general, the longer the interval since proton therapy, the tougher the vitreous had become to cut during PPV, although it is difficult to translate this observation into statistics. As a consequence, whenever VR surgery now becomes indicated, we tend to intervene as soon as the tumor is locally controlled. In 5 cases, we enlarged our indication and performed simultaneous cataract surgery to reestablish transparency of the visual axis. With a radiation threshold as 
low as 0.5 Gy for the induction of cataract to the human lens, this is not surprising. ${ }^{14}$

Anti-vascular endothelial growth factors were scarcely used in this case series, as most of these cases were treated at a time when potential indications for this kind of treatment were only slowly emerging. Although one might speculate that increased use of anti-vascular endothelial growth factors could potentially prevent $\mathrm{VH}$ secondary to proliferative radiation retinopathy in the future, it is more difficult to imagine how these treatments will significantly reduce the apparent mechanical effect of a rupture in the retinal barrier. In this context, it is remarkable to note that in our series 11 of 14 cases with VH requiring PPV also presented a tumor breakthrough in the retina, whereas melanomas with retinal invasion were reported to be present in only $7 \%$ of a control UM population. ${ }^{11}$

Because of the multitude of factors influencing final visual acuity in UM eyes treated with radiotherapy and consequently PPV, it is difficult to draw universal conclusions from a series of 21 eyes. Initial visual acuity, tumor size and location, extent and duration of the serous $\mathrm{RD}$, radiation retinopathy, and/or neuropathy are all factors that, on top of the other indications for PPV (Table 1), will influence visual acuity after PPV. However, the fact that average visual acuity improved indicates that PPV had been justified in the majority of our cases. Overall, anterior melanomas appear to have a better visual outcome after PPV than posterior melanomas because in the former, the posterior pole has not been irradiated.

Regarding safety of PPV after plaque-irradiated posterior UM, Bansal et $\mathrm{al}^{15}$ did not report an increased risk of intraocular, local, orbital, or systemic dissemination of the tumor. Our series on PPV after proton therapy indicates that postoperative IOP requires attention, without being a permanent problem in most cases. With a local tumor control after proton therapy of $98.8 \%,{ }^{8}$ tumor recurrence at the entry ports does not appear to be a problem, in contrast to patients undergoing PPV before tumor treatment. ${ }^{16}$ However, the risk does need to be taken into consideration in those cases where ophthalmoscopic or ultrasonographic tumor regression is not convincing. The only case in this series, in which tumor recurrence had been suspected before PPV, was therefore immediately irradiated after surgery.

An interesting observation is that this series appears to indicate that an eye with UM can only support a limited number of surgical procedures before going into phthisis bulbi. Of the 17 eyes treated once with proton therapy, followed by one PPV, 16 eyes survived, whereas of the 4 eyes having had more than one PPV, only one eye, containing an anterior melanoma, did not go into phthisis bulbi.
The fact that 3 patients developed distant metastases is compatible with our overall Kaplan-Meyer survival curve of UM treated with proton therapy. ${ }^{8}$

In conclusion, PPV after proton therapy is rarely indicated (2\% in our series). It is a safe procedure and plays a role on 3 levels in the follow-up of patients with UM. First, vitrectomy facilitates tumor surveillance through reestablishing transparency of the visual axis. Second, PPV increases the chances of eye retention as it allows both panretinal photocoagulation to avoid neovascular glaucoma and surgical repair of a rhegmatogenous detachment. And finally, macular surgery or removal of a VH will increase visual acuity, especially when the posterior pole has not been irradiated. Vitreoretinal surgery does thus play an important role in maximizing treatment outcome following complications after proton therapy for UM.

Key words: complications, intraocular pressure, melanoma, proton therapy, radiotherapy, uveal melanoma, visual acuity, vitreoretinal surgery, vitreous hemorrhage.

\section{References}

1. Shields JA, Shields CL. Uveal melanoma. In: Shields JA, Shields CL, eds. Intraocular Tumors: An Atlas and Textbook. 2nd ed. Philadelphia, PA: Lippincott Williams \& Wilkins; 2008:69-117.

2. Collaborative Ocular Melanoma Study Group [Corporate Author]. The COMS randomized trial of iodine-125 brachytherapy for choroidal melanoma: V. Twelve-year mortality rates and prognostic factors: COMS report No. 28. Arch Ophthalmol 2006;124:1684-1693.

3. Schalenbourg A, Zografos L. Proton beam radiotherapy of uveal melanoma. In: Spaeth GL, Danesh-Meyer HV, Goldberg I, Kampik A, eds. Ophthalmic Surgery: Principles and Practice. 4th ed. Philadelphia, PA: Elsevier Saunders; 2012:600-602.

4. Dendale R, Lumbroso-Le Rouic L, Noel G, et al. Proton beam radiotherapy for uveal melanoma: results of Curie InstitutOrsay proton therapy center (ICPO). Int J Radiat Oncol Biol Phys 2006;65:780-787.

5. Egger E, Zografos L, Schalenbourg A, et al. Eye retention after proton beam radiotherapy for uveal melanoma. Int J Radiat Oncol Biol Phys 2003;55:867-880.

6. Hamrouni Z, Levy C, Lumbroso L, et al. Results of treating uveal melanoma with proton beam radiation: 10-year followup [in French]. J Fr Ophtalmol 2005;28:833-839.

7. Desjardins L, Lumbroso-Le Rouic L, Levy-Gabriel C, et al. Treatment of uveal melanoma by accelerated proton beam. Dev Ophthalmol 2012;49:41-57.

8. Egger E, Schalenbourg A, Zografos L, et al. Maximizing local tumor control and survival after proton beam radiotherapy of uveal melanoma. Int J Radiat Oncol Biol Phys 2001;51:138-147.

9. Jensen OA. The "Knapp-Ronne" type of malignant melanoma of the choroid. A haemangioma-like melanoma with a typical clinical picture. So-called "preretinal malignant choroidal melanoma". Acta Ophthalmol (Copenh) 1976;54:41-54.

10. Haimovici R, Mukai S, Schachat AP, et al. Rhegmatogenous retinal detachment in eyes with uveal melanoma. Retina 1996; $16: 488-496$. 
11. Bianciotto C, Shields CL, Pirondini C, et al. Vitreous hemorrhage after plaque radiotherapy for uveal melanoma. Retina 2012;32:1156-1164.

12. Bianciotto C, Shields CL, Pirondini C, et al. Proliferative radiation retinopathy after plaque radiotherapy for uveal melanoma. Ophthalmology 2010;117:1005-1012.

13. Foster WJ, Harbour JW, Holekamp NM, et al. Pars plana vitrectomy in eyes containing a treated posterior uveal melanoma. Am J Ophthalmol 2003;136:471-476.
14. Behrens R, Dietze G, Zankl M. Dose conversion coefficients for electron exposure of the human eye lens. Phys Med Biol 2009;54:4069-4087.

15. Bansal AS, Bianciotto CG, Maquire JI, et al. Safety of pars plana vitrectomy in eyes with plaque-irradiated posterior uveal melanoma. Arch Ophthalmol 2012;130:1285-1290.

16. Kavanagh MC, Everman KR, Mitchell Opremcak E, et al. Uveal melanoma with massive extrascleral extension via pars plana vitrectomy sites. Ophthal Plast Reconstr Surg 2008;24:334-336. 